\title{
Endoscopic bougienage for a recurrent esophageal web using a small-caliber-tip transparent hood
}

Cervical esophageal web is a postcricoid thin membrane causing mechanical dysphagia [1]. Though Savary-Gilliard dilatation, balloon dilatation, or surgical myectomy have been reported as effective for dilation of an esophageal web [1-3], there is no standard procedure for dilatation of this condition. We describe a patient with recurrent esophageal web who underwent repeated bougienage with a small-caliber-tip transparent hood (ST hood, DH-15GR or DH-16CR, Fujinon Corp) ( Fig. 1 a, b).

A 79-year-old woman presented with a longstanding history of progressive dysphagia of solid food. Upper gastrointestinal endoscopy revealed an annular stricture caused by a smooth diaphragm in the cervical esophagus. Balloon dilatation was performed under fluoroscopic guidance. However, follow-up endoscopy revealed the recurrence of the stricture. Next, we used a small-caliber-tip transparent hood for the bougienage. The tip of the hood attached to an endoscope was positioned at the center of the stricture ( $\bullet$ Fig. 2). The stricture was then passed through with a push of the endoscope. The mucosal tear was carefully observed after passage of the endoscope to ensure that no perforation had occurred ( $\bullet$ Fig. 3). Repeat bougienage was performed every 3 months to maintain swallow function.

Originally designed for submucosal dissection in endoscopic submucosal dissection, the small-caliber-tip transparent hood is a tapered transparent hood attached to the tip of an endoscope [4]. Bougienage with such a hood has four advantages. 1) Direct observation of stenosis is safer than a blind maneuver. 2) It is difficult to observe a postcricoid area by endoscopy. Observation of a mucosal tear after bougienage with a small-caliber-tip transparent hood is easier than without, as shown in Fig. 3. 3) Fluoroscopic guidance is not needed. 4 ) The cost of the hood is one-tenth that of a dilatation balloon in Japan. Thus, this procedure was shown to be effective for repeat bougienage of a cervical esophageal web.
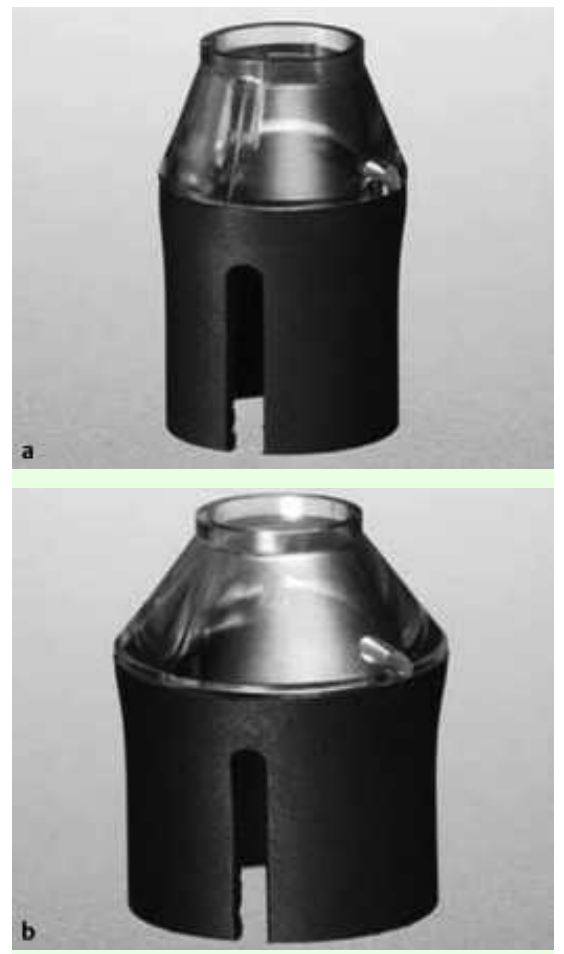

Fig. 1 a DH-15GR for a gastroscope. b DH16CR for a colonoscope.

\section{S. Itaba, K. Nakamura, H. Akiho, R. Takayanagi}

Department of Medicine and Bioregulatory Science, Graduate School of Medical Sciences, Kyushu University, Fukuoka, Japan

\section{References}

1 Sreenivas DV, Kumar A, Mannar KV et al. Results of Savary-Gillard dilatation in the management of cervical web of esophagus. Hepatogastroenterology 2002; 49: $188-$ 190

2 Lindgren S. Endoscopic dilatation and surgical myectomy of symptomatic cervical esophageal webs. Dysphagia 1991; 6: 235 238

3 Enomoto $M$, Kohmoto $M$, Arafa UA et al. Plummer-Vinson syndrome successfully treated by endoscopic dilatation. J Gastroenterol Hepatol 2007; 22: 2348-2351

4 Yamamoto $H$. Technology insight: endoscopic submucosal dissection of gastrointestinal neoplasms. Nat Clin Gastroenterol Hepatol 2007; 4: $511-520$

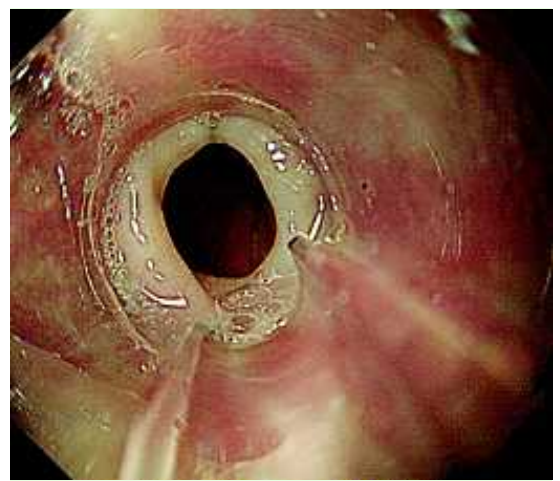

Fig. 2 Upper gastrointestinal endoscopy reveals a cervical esophageal web through the small-caliber-tip transparent hood. The tip of the hood attached to an endoscope is positioned at the center of the stricture.

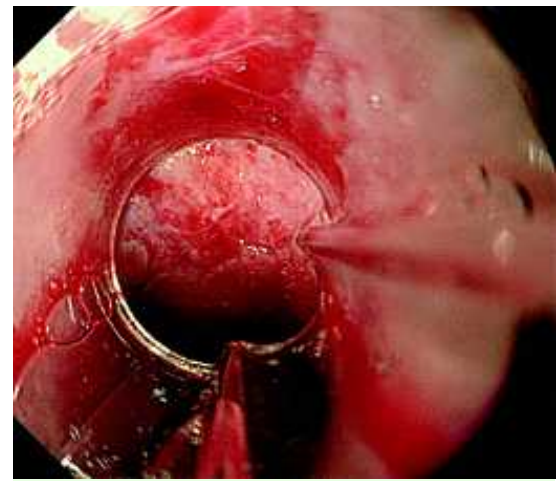

Fig. 3 The mucosal tear was carefully observed after passage of the endoscope to ensure that no perforation had occurred.

Bibliography

DOI $10.1055 / \mathrm{s}-2008-1077424$

Endoscopy 2008; 40: E198

(c) Georg Thieme Verlag KG Stuttgart · New York . ISSN 0013-726X

\section{Corresponding author}

\section{S. Itaba, MD}

Department of Medicine and

Bioregulatory Science

Graduate School of Medical Sciences

Kyushu University

Fukuoka 812-8582

Japan

Fax: +81-92-6425287

itaba@intmed3.med.kyushu-u.ac.jp 